\title{
基于建筑施工中的防水防渗施工技术研究
}

高金超

DOI:10.32629/ems.v2i2.713

[摘 要] 新时期经济飞速发展,在此背景下人们的生活水平显著提升,对建筑工程质量的要求逐步提升。建筑物渗漏 水问题是建筑行业无法有效解决的问题之一, 对建筑行业发展产生了极大的影响。建筑物如果发生渗漏水情况, 不但 会影响建筑物的美观和使用功能,同时对建筑物的使用年限和使用效果也有较大的影响。为了保证人们的生活和生 命财产安全,本文对建筑施工中的防水防渗技术进行深入的研究,并提出防水防渗的有效施工措施。

[关键词] 建筑工程;防渗水;施工技术;有效措施

\section{1 建筑施工中防水防渗的重要作用}

1.1 最大程度延长建筑的使用期限

建筑质量受到多种因素的影响，渗水渗漏问题就是 其中一个重要的影响因素。不仅会影响建筑整体质量,还 会影响建筑中其他基础设施,同时也会影响人们的正常使 用。在建筑施工中应用防水防渗施工技术, 不但能够大幅 提升建筑的防水防渗能力, 保证建筑中的钢筋的刚度和强 度符合工程要求, 能够尽量延长建筑的使用期限。因此在 施工过程中, 需要严格规范施工流程和施工工艺, 合理采 取防水防渗施工技术,保证建筑的质量和后续使用效果。

\section{2 提高建筑物质量和稳定性}

建筑施工中如果没有有效的防水防渗措施, 那么后 期投人使用后会遇到很多问题，例如水的侵蚀等容易导 致建筑物的整体受到损坏, 内部材料被腐蚀等严重的问 题,因此施工过程中一定要根据实际情况, 合理应用防水 防渗技术进行防护, 提升建筑物的耐久性, 确保后期的使 用安全。能够让使用者获得良好的使用体验,避免因为渗 漏影响正常生活, 甚至对建筑质量和使用寿命造成严重 的影响。能够为人们提供更安全和稳定的使用效果, 为保 证人们的生命和财产安全奠定坚实的基础。

\section{3 显著降低后期维护成本}

建筑施工中应用的防水防渗技术, 不但能够延长建 筑使用期限, 同时还能显著降低后期的维护成本, 能够避 免产生额外费用, 能够表现出建筑企业的质量和水平, 为 施工企业赢得良好的口碑 ${ }^{[1]}$ 。施工过程中根据实际施工 情况,合理应用防水防渗技术,能够有效避免渗水带来的 影响, 从而能够降低建筑的后期维修和维护次数, 避免破 坏和影响建筑内部设施,确保建筑的良好使用功能。

\section{2 建筑工程渗漏分析}

在建筑施工中经常出现渗漏的部位主要包括外墙、 屋面、厨卫和地下室,施工中要对注意对这些部门合理应 用放水和防渗技术,避免发生渗漏问题。

\section{1 建筑外墙渗漏}

造成建筑外墙渗漏主要的原因为施工不规范, 例如
外墙施工中在砌筑或是穿孔时遗留的漏水点。具体来说, 在施工过程中, 没有严格按照施工标准进行砂浆砌筑, 或 是砌砖过程中留下了过大的空隙, 后续施工的时候没有 及时修复,可能会引发外墙渗水。外墙施工中会用到大量 管制工具,因外墙表面存在大量的孔洞,这也是导致渗漏 的主要原因。

\section{2 建筑屋面渗漏}

导致建筑屋面渗漏的原因有很多种, 渗漏对建筑工 程质量影响最大的因素之一。通常建筑施工中导致屋面 渗漏的原因主要有: 施工时没能规范的应用防水防渗施 工技术,会导致屋面存在裂缝、应力膨胀等情况。工程中 使用的防水材料不符合施工技术要求, 无法满足防渗漏 标准，甚至有些施工单位在屋面施工时会利用质量不合 格的材料,无法有效保证防水防渗质量。屋面的接触部位 是最容易出现渗漏的部位，如果屋面施工时没有合理处 理连接位置, 就会留下极大的安全隐患, 提高了后期出现 渗漏的可能性。

\section{3 厨卫渗漏}

欴房和卫生间是建筑中用水量最大的两个区域,如 果施工技术不规范, 容易造成渗漏。厨房和卫生间中存在 大量的管道,还包括交叉的管路,如果水管发生渗漏会影 响整体使用效果。厨卫的渗漏主要是因为管路导致的,㕌 卫中的管路会承受较大的压力, 一旦出现堵塞就会导致 出现渗漏, 渗漏情况会受到水压的影响逐步严重, 施工过 程中需要重点关注。

\section{4 建筑地下室渗漏}

建筑工程中地下室是基础项目, 同时地下室的渗漏 问题也是较为突出的, 渗漏是因为多种因素共同作用导致 的。通常较为常见的影响因素为地下室内存在的管道开 裂或是损坏; 管道和混凝土之间存在缝隙, 管道内流出的 水会从缝隙下渗到地下室 ${ }^{[2]}$ 。因此混凝土和管道是地下室 渗漏需要重点关注的,是应用防水防渗技术主要位置。

3 建筑工程施工中应用防水防渗技术的具体措施

3.1 合理做好防水防渗设计规划 
建筑工程施工中合理应用防水防渗技术，应该从工 程的规划设计阶段就提高对防渗漏的重视程度, 确保工 程设计的科学合理, 能够对施工流程和施工技术进行有 效指导。避免因为工程设计不合理影响建筑施工的防渗 漏能力, 导致建筑工程存在隐患, 投入使用后会产生各种 问题。工程设计人员必须考虑到不同区域的防水防渗设 计侧重点、施工技术、施工工艺是各不相同, 一定要具体 分析不同空间的实际用途和使用功能特点, 才能确保建 筑工程项目具备良好的防水防渗能力。施工中一定要特 别注意,避免存在遗漏的区域,会给其他部门造成不同程 度的影响。设计中要正确使用防水卷材或是防水涂料, 同 时也要明确施工工艺和施工操作流程, 严格按照标准施 工才能满足防水防渗技术的需要。要对完成的设计方案 进行严格的评价和审查, 确保设计方案的全面和科学, 需 要详细检查是否存在遗漏的部分。设计人员和施工单位 还要进行技术交底, 对特殊工艺和特殊技术要进行重点 培训,能够确保符合施工要求。

3.2 施工中要重点关注容易发生渗漏的部位

建筑工程施工中应用防水防渗技术, 必须对容易发 生渗漏部分进行严格把关, 才能确保获得最佳的施工效 果,降低出现渗漏的可能性。建筑工程项目施工中防水防 渗技术应用最广泛的区域, 是建筑中最容易发生渗漏的 部位, 例如建筑物墙体、地下室、建筑外墙窗口以及遊卫 等, 施工过程中必须对这些区域进行重点关注, 根据实际 情况合理应用防水防渗技术。

3.2.1 建筑外墙体施工时, 务必严格按照施工规范进 行作。施工方要结合设计图纸和工程实际情况, 深人施工 现场全面了解施工环境和其他具体情况。施工时需要根 据实际情况合理对外墙进行加固,例如可以加配钢丝网、 安置分隔缝。最大程度的保证墙体平整, 避免外墙凹凸不 平。墙体外层要利用混凝土构筑, 避免雨水入侵产生影 响。如果外墙中存在缝隙, 那么更加容易受到雨水的影 响, 施工时如果发现墙体存在裂缝, 首先需要清理墙面和 缝隙中的杂物和灰尘, 然后使用水泥浆将缝隙严密封堵, 同时需要进行封堵的还有施工阶段留下的孔洞或缝隙, 施工时要在水泥中加人膨大剂, 确保封堵的严密性 ${ }^{[3]}$ 。施 工时如果发现其他情况, 还需要根据具体情况采取合理 的处理措施。

3.2.2 建筑工物地下室通常都存在众多的管道, 如果 地下室如果发生渗漏, 会对建筑的正常使用形成严重的影 响,因此施工中必须要高度重视。地下室中存在较多接缝, 属于特殊的施工区域,因此要注意采用施工工艺和施工技 术。在施工作业时, 必须选择优质的防水材料, 施工时尽量 要在建筑区域的墙体均匀的涂抹防水材料, 有效提升地下 室区域整体的防水防渗能力。

3.2.3 欴房和卫生间是建筑物中用水量最大也是渗漏
文章类型: 论文 | 刊号( ISSN ):2705-0637(P)/2705-0645(O)

高发的区域,因此施工时需要重点关注,应用合理的施工 技术和施工工艺, 确保使用优质和高效的防水材料,根据 建筑实际用途, 将这两个重点区域的防水层进行优化,也 可用采取打孔方式进行施工, 施工中要对要注意连接部位 的防水和防渗处理,避免出现渗漏情况, 导致建筑物的内 部结构被侵蚀和损坏,提升建筑总体质量和使用效果。

\section{3 防水材料的选择和质量控制}

建筑施工时应用防水防渗技术, 想要获得最佳的防 水防渗效果,关键要严格控制防水材料质量。需要综合考 虑建筑的不同区域的使用要求和使用特点等方面, 从而 选择符合工程要求的防水材料。只有确保根据不同材料 采取合理的施工技术,才能获得良好的工程整体效果,避 免建筑物投人使用后出现渗漏问题。选择防水材料时首 先全面考虑材料的供应单位、材料质量和材料型号等因 素,确保选择市场信誉度好,正规大厂生产的,经过检测符 合行业要求的材料,才能确保获得良好的防水防渗效果。 如果施工中发现材料不符合工程要求或是存在质量问 题, 需要马上更换, 已经使用的全部进行整改, 辟免无法通 过验收对施工企业造成严重的影响。新时期建筑材料频 繁更新换代,新型防水材料不但质量好, 同时更加节能环 保,防渗漏性能更加优异。可以在施工过程中考虑使用, 特别是在特殊部位应用, 有效提升防水防渗能力。

\section{4 强化质量检测和查验工作}

为了确保建筑工程合理应用防水防渗施工技术,施工 时要不定期的对防水防渗性能进行质检和查验, 确保施工 技术符合工程要求。如果检查出施工不符合工程标准,需 要及时上报并进行有效处理。工程的防水防渗技术进行 质检,不仅要关注防水防渗技术的合理应用,还需要关注 和分析特殊结构和部位, 确保建筑物防水防渗性能的稳定 性和持久性,从而保证建筑物的长期、安全的使用。

\section{4 结束语}

对于建筑工程来说渗漏问题是极为严重的, 不仅会 影响建筑物的使用年限, 还会影响正常使用甚至引发安 全事故。施工中需要重视强化防水防渗技术能力, 严格按 照施工设计方案进行作业, 不断进行总结和反思, 提升防 水防渗施工技术能力, 促进建筑行业健康发展。

\section{[参考文献]}

[1]肖明.建筑工程施工中防水防渗施工技术分析与 研究[J].住宅与房地产,2018,507(22):169.

[2]王丽雅.建筑工程施工中的防水防渗施工技术 [J].住宅与房地产,2018,(11):203.

[3]项增远.建筑工程施工中防水防渗施工技术分析 [J].绿色环保建材,2018(2):200.

\section{作者简介}

姓名: 高金超; 性别: 男; 民族: 汉; 籍贯: 山东; 身份 证号:370181198910020013 